Equally significant appears to have been an announcement nine days before Christmas by the managers of a website known irreverently as The Motley Fool (TMF) that they had decided to purchase $\$ 50,000$ of shares in Celera Genomics to add to their portfolio of 'rule breaker' companies.

The impact of the announcement, coming from a group of investors who had been among the first to spot key Internet stocks such as America OnLine - whose shares, purchased in 1994 at 46 cents, are now worth more than $\$ 70$ - was electric. While the number of shares purchased in Celera had previously been running at about 150,000 a day, this was multiplied overnight by a factor of more than ten.

The explosion in demand was rapidly reflected in the price of Celera stock. Having hovered around $\$ 40$ for much of the autumn, it had been growing steadily to reach a value of $\$ 72$ by 16 December, the day of the TMF announcement.

Within three trading days the value of the shares had shot up to $\$ 125$, and this momentum was maintained in the days to come. The shares reached a high for the year of $\$ 193$ on 30 December; the previous

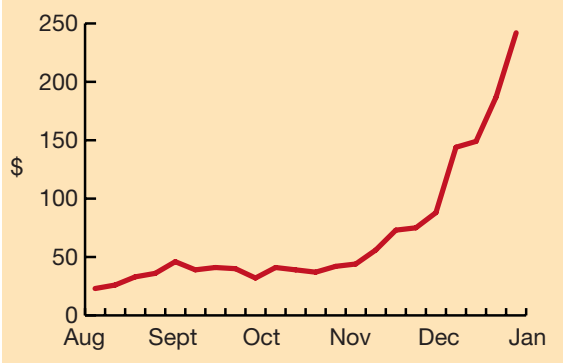

On the up and up: Celera's share price has taken off dramatically in recent weeks.

August, they had been down to $\$ 22$.

After dropping slightly as a result of profit-taking in the days immediately after the Christmas break, the shares took off again, defying predictions that the preChristmas increase in value would be shortlived. Last Friday, trading in Celera stock was halted when the company announced plans for its Monday press conference.

Analysts say that many of those who have been buying up genomics stocks at such speed seem to be individuals who have already profited from the recent growth in the value of Internet stocks, and have been attracted to genomics because of the similarities between the two fields.

"People have been saying that

biotechnology is like the Internet, but until recently the stock has been much cheaper," says Genghis Lloyd-Davies of Credit Suisse First Boston.

Managers at TMF reflect this new-found enthusiasm. The decision to invest heavily in Celera was taken after assessing the extent to which the company fitted the strict criteria they have laid down for the selection of 'rule breaker' stock.

One of these, as described in a statement explaining the investment last month, was the fact that Celera appeared to be the dominant company in a rapidly growing area of commercial significance. "Celera has more 'momentum' - more speed - than any other company that we've ever bought," said the statement.

TMF managers acknowledge that their decision to invest in Celera reflects a longterm commitment. Dave Gardner, one of the founders of the website says: "We believe that in this coming century more value will be created in biotechnology than in any other technology."

David Dickson

\title{
Inadequate optics 'threat to US laser facility'
}

Washington

A series of technical obstacles could block completion of the US National Ignition Facility (NIF), according to an interim project review delivered this week to Bill Richardson, the Secretary of Energy.

The huge laser facility is under construction at the Lawrence Livermore National Laboratory in California. But major optical components may be unable to carry the NIF lasers at the intensity originally envisaged, says the review, by a task force of the Secretary of Energy's Advisory Board.

Optical damage will occur in these fused silica lenses at a lower intensity of laser light than was expected when the NIF was designed, because they will be operating in a vacuum - a conclusion that the authors admit is "a surprise".

They also say it will be hard to keep the equipment clean, because of "very cramped assembly areas" in the NIF building. And they warn that it will be difficult to order and procure 30,000 small optics components to adequate specification.

But the task force, chaired by John McTague, former technical director of the Ford Motor Company, concludes that the NIF can still be completed, although it will take longer and cost more than planned. "The task force has not uncovered any technical obstacle that would clearly prevent completion and operation of the NIF sys- tem," said McTague, releasing the interim report on Monday (10 January).

The task force recommends that Livermore should assemble 96 lasers - half the original total - and use each of them at half their originally designed power to prevent damage to the fused silica optics. It then suggests a pause in the project before assembling the other lasers and raising the power intensity to the original design level by 2007 four years later than originally planned.

Asked if overruns on the $\$ 1.2$ billion project would be much more than $\$ 300$ million - widely floated since problems emerged on the project last September - McTague said, "I don't know". He agrees that construction of the NIF began with "unrealistic" expectations, "because there wasn't enough fleshing out of the 'hows' of the project".

The task force criticizes Vic Reis, assistant secretary of energy responsible for defence programmes when NIF was started, for allowing it to proceed with contingency funding of only 15 per cent. This "may be appropriate for the construction of an apartment building, [but it] is too low for this challenging and unique project," says the review, adding that such projects should have a contingency of 30 or 35 per cent.

It also says that the "scientific culture" of the Lawrence Livermore laboratory hindered the execution of such a large engineering project, and criticizes its director, Bruce
Tarter, for failing to take direct responsibility for the NIF - even now. "The project needs to report directly to him," McTague says. "He needs to insert himself into the process." Tarter was unavailable for comment.

The task force found, however, that problems with cleanliness during laser assembly inside the NIF building could be solved by importing outside expertise. These problems were initially cited by laboratory officials as the main reason for the project's problems (see Nature 401, 101; 1999), although the McTague review spells out far broader technical and management difficulties running across the entire project.

A spokesman for the Department of Energy said that it would respond to the review when the final report was deliveredit is expected in the spring. Critics of the NIF say the review's technical content shows that the project won't work. "What makes sense is to halt the project, build one beam and see if it works," says Chris Paine of the Natural Resources Defense Council, an anti-nuclear group that opposes the project.

But Burt Richter, former director of the Stanford Linear Accelerator Center and a member of the task force, rejects charges from environmentalists that the review had been too kind. "This is a hard-hitting report," Richter says. "It says that a laser intensity of half the design is a shoo-in, but anything else is quite risky.” Colin Macilwain 